\title{
A tethered-balloon PTRMS sampling approach for surveying of landscape-scale biogenic VOC fluxes
}

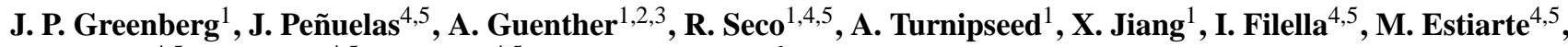 \\ J. Sardans ${ }^{4,5}$, R. Ogaya ${ }^{4,5}$, J. Llusia ${ }^{4,5}$, and F. Rapparini ${ }^{6}$ \\ ${ }^{1}$ Atmospheric Chemistry Division, National Center for Atmospheric Research, Boulder, CO, USA \\ ${ }^{2}$ Pacific Northwest National Laboratory, Richland WA, USA \\ ${ }^{3}$ Washington State University, Pullman WA, USA \\ ${ }^{4}$ CREAF, Cerdanyola del Vallès 08193, Barcelona, Catalonia, Spain \\ ${ }^{5}$ CSIC, Global Ecology Unit CREAF-CSIC-UAB, Cerdanyola del Vallès 08193, Barcelona, Catalonia, Spain \\ ${ }^{6}$ Institute of Biometeorology, National Research Council Via Gobetti 101, 40129 Bologna, Italy
}

Correspondence to: J. P. Greenberg (greenber@ucar.edu)

Received: 8 January 2014 - Published in Atmos. Meas. Tech. Discuss.: 31 January 2014

Revised: 20 May 2014 - Accepted: 12 June 2014 - Published: 23 July 2014

\begin{abstract}
Landscape-scale fluxes of biogenic gases were surveyed by deploying a $100 \mathrm{~m}$ Teflon tube attached to a tethered balloon as a sampling inlet for a fast-response proton-transfer-reaction mass spectrometer (PTRMS). Along with meteorological instruments deployed on the tethered balloon and a $3 \mathrm{~m}$ tripod and outputs from a regional weather model, these observations were used to estimate landscape-scale biogenic volatile organic compound fluxes with two micrometeorological techniques: mixed layer variance and surface layer gradients. This highly mobile sampling system was deployed at four field sites near Barcelona to estimate landscape-scale biogenic volatile organic compound (BVOC) emission factors in a relatively short period (3 weeks).

The two micrometeorological techniques were compared with emissions predicted with a biogenic emission model using site-specific emission factors and land-cover characteristics for all four sites. The methods agreed within the uncertainty of the techniques in most cases, even though the locations had considerable heterogeneity in species distribution and complex terrain. Considering the wide range in reported BVOC emission factors for individual vegetation species (more than an order of magnitude), this temporally short and inexpensive flux estimation technique may be useful for constraining BVOC emission factors used as model inputs.
\end{abstract}

\section{Introduction}

Observations of landscape-level fluxes of biogenic volatile organic compounds (BVOCs) are needed in order to parameterize and evaluate the emissions used for regional air quality and global climate models (Guenther et al., 2012). Estimates of these fluxes have been made using several techniques (Greenberg et al., 1999; Guenther et al., 1996a, b; Karl et al., 2007), including the extrapolation of leaf-level emissions to landscapes (inventory method), tower-based surface layer micrometeorological techniques (eddy covariance, relaxed eddy accumulation, and surface layer gradient methods), and tethered-balloon-based mixed layer techniques (mixed layer gradients calculations and inverse modeling). There are a number of difficulties associated with each of these techniques. For the inventory approach, a large representative area must be surveyed for vegetation species composition and the biomass of each species present, and the emission capacities of specific BVOC emissions must be measured, along with the dependence on the environmental variables that effect these emissions (e.g., temperature and light). Obtaining representative emission capacities using enclosure techniques is especially difficult for BVOC emissions that are sensitive to the disturbance associated with placing enclosures on plants (Niinemets et al., 2011). The assumptions required for tower-based micrometeorological techniques generally include a homogeneous distribution of 
emission sources over a flat, horizontal terrain. Most micrometeorological flux measurements are conducted on an above-canopy, stationary tower that must be constructed and equipped with chemical and micrometeorological instrumentation. Inverse modeling of emissions requires estimates of boundary later heights and the major chemical sinks. For most BVOC, this includes the hydroxyl radical, which is difficult to measure or accurately estimate. All techniques are associated with significant cost and effort.

MONTES ("Woodlands") was a multidisciplinary international field campaign in July 2010 aimed at measuring energy, water, and especially gas exchange between vegetation and atmosphere from four representative landscapes in the MONTES region: a gradient from short semi-desert shrubland to tall wet temperate forests in northeast Spain in the northwestern Mediterranean Basin (Peñuelas et al., 2013). The measurements described here were performed at a semidesertic area (Monegros), at a coastal Mediterranean shrub land area (Garraf), at a Mediterranean holm oak forest area (Prades) and at a wet temperate beech forest (Montseny).

BVOC emission models, such as the Model of Emission of Gases and Aerosols from Nature, version 2.1 (MEGAN2.1, Guenther et al., 2012), predict large differences in BVOC emissions from the four MONTES landscapes, indicating a potential for changes in atmospheric chemistry associated with climate-driven changes in land cover in this region (e.g., the conversion of a beech forest to a Mediterranean shrubland due to a drying climate). Confidence in this predicted emission change is limited by a lack of landscape-scale measurements to evaluate the model predictions of these differences. In this manuscript, we describe the implementation and evaluation of a short-term approach for surveys of landscape-scale isoprene, monoterpenes, and several oxygenated volatile organic compounds emissions from the four MONTES landscapes. The approach includes two independent tethered-balloon-based flux measurement techniques: mixed layer variance (MLV) and surface layer vertical gradients (SLG). The flux estimates are compared and used to evaluate emissions estimated using intensive landscape inventory estimates.

\section{Experimental details}

\subsection{Site descriptions}

The sites may be characterized as hilly (Montseny) to steep and rugged (Garraf, Monegros, Prades) (see Peñuelas et al. (2013) for vegetation details and topographical information). Garraf (81\% shrubland, $12 \%$ Pinus halepensis) and Monegros (51\% semi-desertic shrubland, $46 \%$ cropland) are more sparsely vegetated. The Prades landscape is a Mediterranean holm oak forest (42\% Quercus ilex, $27 \%$ Pinus nigra, $14 \%$ Pinus sylvestris, $5 \%$ Quercus pubescens), while Montseny is covered by a temperate beech forest ( $80 \%$ Fagus sylvatica,
$5 \%$ Quercus ilex)., The balloon launch sites for Garraf and Monegros were clearings ( $\sim 25 \mathrm{~m}$ diameter) near isolated buildings. At Prades a narrow grassy terrace in the hillside $(\sim 10 \mathrm{~m} \times 25 \mathrm{~m})$ was used for balloon operations. In Montseny, however, the balloon was launched from a large grassy field, approximately $50 \mathrm{~m} \times 200 \mathrm{~m}$, surrounded by a predominantly beech forest.

\subsection{Tethered-balloon sampling using PTRMS}

A $12 \mathrm{~m}^{3}$ helium-filled blimp-shaped balloon (Blimpworks, Statesville, NC, USA) was used to lift the inlet of a Teflon sampling line $(6.35 \mathrm{~mm}$ outside diameter, $4.83 \mathrm{~mm}$ inside diameter) to altitudes up to $100 \mathrm{~m}$ above the surface. The outlet end of the Teflon line (ground level) was connected to a sampling pump (model 1023-101Q-G605X, Gast Manufacturing Co., Benton, MI, USA). Ambient air was pulled through the inlet at various altitudes at a flow rate of approximately $10 \mathrm{~L}$ per minute, controlled by a mass flow meter just before the inlet of the pump.

Real time methanol, acetaldehyde, acetone, acetic acid, isoprene, and monoterpene measurements were performed by means of a high-sensitivity proton-transfer-reaction mass spectrometer with a quadrupole mass analyzer (PTRMS-QMS, Ionicon Analytik GmbH, Innsbruck, Austria; Lindinger et al., 1998). The PTRMS was housed inside an air-conditioned mobile caravan located a few meters away from the balloon launch site. The PTRMS inlet was connected with a tee in the balloon sampling line upstream of the flow controller and pump. Visual inspection confirmed that no condensation occurred in the heated inlet. Drift tube pressure, temperature and voltage were typically maintained at $0.22 \mathrm{kPa}, 50^{\circ} \mathrm{C}$ and $580 \mathrm{~V}$, respectively, which gave a primary ion count in the range of $6--8 \times 10^{6}$ ion counts per second (cps). The sensitivity of the PTRMS for each atomic mass unit was measured on the first day and at least once later at each site using a gas standard (Restek Corp, Bellafonte, PA, USA), which contained aromatic compounds at a nominal concentration of 1 ppmv each. For those compounds not contained in the gas mixture, empirical sensitivities were calculated based on the instrument-specific transmission characteristics and individual ion-molecule reaction rates (Zhao and Zhang, 2004). Individual terpenes are not distinguished by the PTRMS technique; the total of terpenes observed was estimated from the response of the instrument to $\alpha$-Pinene. The instrument background was monitored by sampling ambient air that had passed through a glass tube packed with platinum on alumina catalyst heated to $400{ }^{\circ} \mathrm{C}$ to remove volatile organic compound (VOCs).

Electricity to operate the instrumentation was supplied by the local power grids. 


\subsection{Meteorological measurements}

Meteorological parameters (air temperature, relative humidity, pressure (altitude), wind speed, and direction) were recorded during all balloon deployments using a portable weather station (Kestrel 4500; Nielsen-Kellerman, Boothwyn, PA, USA), attached $0.5 \mathrm{~m}$ beneath the balloon. Sensors for net radiation (REBs, model Q*7, Seattle, WA, USA) and direct and diffuse photosynthetic radiation (Delta $\mathrm{T}$ Devices, model BF3, Cambridge, UK) were mounted on a $1 \mathrm{~m}$ horizontal boom at the top of a $3 \mathrm{~m}$ tripod. Turbulent fluxes of sensible and latent heat were measured by eddy covariance with a 3-D sonic anemometer (RM Young, model 81000 V, Traverse City, MI, USA) and a Krypton hygrometer (Campbell Scientific, Model KH20, Logan, UT, USA) atop the same tripod. The radiometers and hygrometer signal outputs were integrated with the sonic anemometer wind velocity and virtual temperature signals and then logged at $10 \mathrm{~Hz}$ with a laptop computer. Sensible heat fluxes were derived from the covariance between the vertical wind velocity, $w$, and the sonic-derived virtual temperature, $T_{\mathrm{s}}$. Latent heat fluxes were similarly derived from the covariance of $w$ with the fast fluctuations in water vapor measured by the hygrometer. Prior to computation of the covariance, wind vectors were rotated to a set mean (Kaimal and Finnigan, 1994). Water vapor fluctuations were also corrected for $\mathrm{O}_{2}$ absorption (ftp://ftp.campbellsci.com/pub/csl/ outgoing/uk/technotes/4-93mp_appa.pdf) and density corrections due to temperature (Webb et al., 1980). Wind speed and direction, along with turbulent moments such as the friction velocity, were also derived from the rotated wind velocities.

\subsection{WRF-Chem model simulations}

Several variables used in the estimation of fluxes were determined from regional numerical model simulations. These included boundary layer height, sensible heat flux, convective velocity scale, stability conditions, etc. To quantify these variables, we conducted a numerical simulation using version 3.2 of the weather research and forecasting (WRF) model with chemistry (WRF-Chem, Grell et al., 2005 ) at a $30 \mathrm{~km}$ spatial resolution over an extensive area surrounding the measurement sites in Spain. WRF-Chem is a meteorology-chemistry model developed collaboratively among several groups including the National Center for Atmospheric Research (NCAR) and the US National Oceanic and Atmospheric Administration (NOAA). In this work, we used the mass coordinate version of the model, Advanced Research WRF (ARW) (Skamarock et al., 2005). The gas-phase chemical mechanism used is the Regional Acid Deposition Model version 2 (RADM2) (Stockwell et al., 1990). Anthropogenic emissions of $\mathrm{NO}_{\mathrm{x}}, \mathrm{SO}_{2}, \mathrm{VOCs}$, $\mathrm{PM}_{2.5}$, and $\mathrm{PM}_{10}$ were taken from the global inventoryIntercontinental Chemical Transport Experiment (Phase B)
(INTEX-B) inventory (Zhang et al., 2009). In addition, the 2000 Reanalysis of Tropospheric Chemical Composition (RETRO) (http://retro.enes.org/index.shtml) database was used when INTEX-B inventory data were not available. Biogenic emissions were calculated online using the Model of Emissions of Gases and Aerosols from Nature (MEGAN) biogenic emissions module, version 2.04 (Guenther et al., 2006) in the WRF-Chem model. We used the dry deposition for trace gases based on a surface resistance parameterization developed by Wesely (1989). Other parameterizations used in the simulations include a microphysics scheme (Lin et al., 1983), an ensemble cumulus parameterization scheme (Grell and Devenyi, 2002), the Yonsei University planetary boundary layer (PBL) scheme (Hong and Pan, 1996), the Goddard shortwave radiative transfer model (Chou and Suarez, 1994), the Rapid Radiative Transfer Model Longwave Radiation scheme (Mlawer et al., 1997), and the Noah land surface model (Chen et al., 1997). The global 1-degree NCEP (National Centers for Environmental Prediction) Final Analyses (FNL) data were used for initial and boundary conditions for meteorology. A 1-month (July 2010) simulation covering the measurement period was conducted. We used the initial and boundary conditions for the chemical species similar to the one used in Jiang et al. (2008). To minimize the effect of initial conditions on model results, we followed the method used in Jiang et al. (2008) to include 2 additional days (29 and 30 June) in the simulation to spin-up the initial conditions for atmospheric concentrations of several different emitted species.

\subsection{Flux estimate techniques}

\subsubsection{Mixed layer variance technique}

In the atmospheric mixed boundary layer, turbulence from sensible heat flux is responsible for most of the vertical transport (surface friction is negligible). We estimated landscapelevel fluxes at the bottom of the mixed layer as

$\operatorname{Flux}_{C}=0.77 \sigma_{c} w^{*}\left(z / z_{i}\right)^{1 / 3}$,

where $\sigma_{c}$, is the standard deviation of scalar $C$ (concentration), $w^{*}$ is the convective velocity scale $\left(w^{*}=\right.$ $\left.\left((g / T) H z_{i}\right)^{1 / 3}\right), g$ is acceleration due to gravity $\left(9.8 \mathrm{~m} \mathrm{~s}^{-2}\right)$, $T$ is temperature $(\mathrm{K}), H$ is the sensible heat flux, $z$ is the height at which the standard deviation measurement is made, and $z_{i}$ is the height of the boundary layer at the time of the measurement (Lenschow, 1995). The direction of the flux was determined from the slope of the gradient of concentration in the surface layer (see below).

Boundary layer heights were not measured during the experiment; these were taken from the WRF model and are presented in Fig. 1. Sensible heat flux $(H)$ was measured using a sonic anemometer deployed at each site. For Garraf and Monegros, the canopy of the shrubland vegetation was lower than the height of the sonic anemometer, which was 

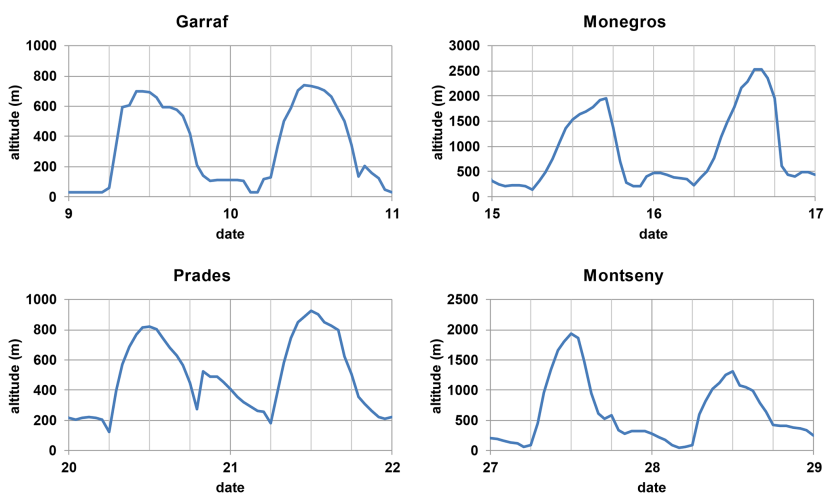

Figure 1. Boundary layer heights (m) computed by the WRF model for the days of sampling at the four landscapes studied.

situated within an undisturbed fetch in the landscape. For Prades, the sonic anemometer was located in a grassy clearing of a mostly closed canopy forest (canopy height $\sim 10 \mathrm{~m}$ ); in Montseny, the sonic anemometer was erected in a large meadow surrounded by beech forest (canopy height $\sim 15 \mathrm{~m}$ ). The measured sensible heat fluxes observed were compared with those derived from the WRF (Fig. 2). The $H$ value derived from observations in Prades and Montseny (where the location of the sonic anemometer was below the canopy height and so not representative of the landscape average) does not agree with the landscape-scale sensible heat flux estimated by the model. For Garraf and Monegros, where the observations were made in a more representative fetch, there was good agreement between model and observations. It was consequently decided to use the model calculated $H$ for all sites to calculate the convective velocity scale $\left(w^{*}\right)$. The standard deviation for each VOC, $\sigma_{c}$, was calculated for each $1 / 2 \mathrm{~h}$ period that the balloon sampling line was positioned at a height of $100 \mathrm{~m}$; selected VOCs (methanol, acetone, isoprene, monoterpenes) were sequentially measured at $5 \mathrm{~Hz}$ by PTRMS; One second was required to measure the selected ions for $(33,69$ and 81, respectively, as well as the first two water ions at 21 and $39 \mathrm{~m} / z$ ).

The MLV technique does not indicate the direction of the flux during the time of the calculation. The direction was given by the alternate surface gradient profiles. Excepting the need for the direction of the flux, the MLV measurements may be made continuously for many hours.

\subsubsection{Surface layer gradient technique}

The same measurement system used for the mixed layer variance technique was also used for the surface layer gradient approach. For this measurement, the balloon was raised sequentially to altitudes $5,20,40,60,80$, and $100 \mathrm{~m}$ and then returned to the surface in the reverse order. The balloon was held at each altitude for $10 \mathrm{~min}$, during which time the PTRMS was used to measure the protonated masses of methanol $(m / z 33)$, acetaldehyde
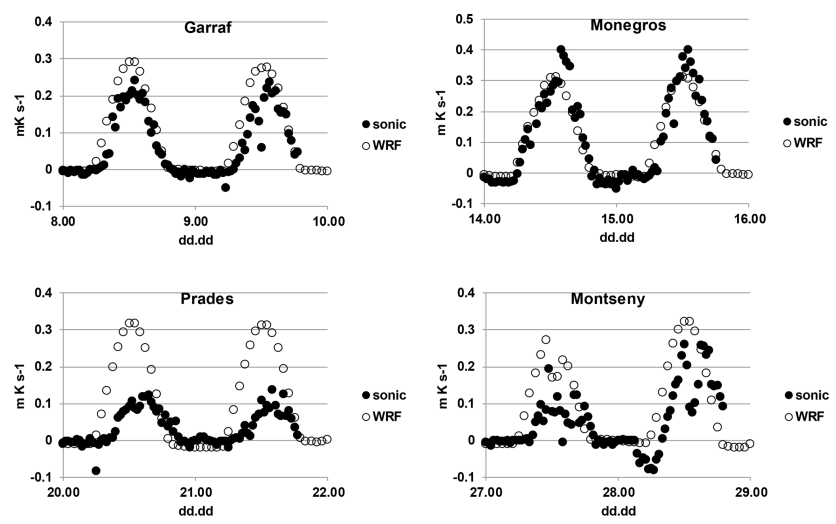

Figure 2. Comparison of the sensible heat flux $\left(\mathrm{m} \mathrm{degK} \mathrm{s}^{-1}\right)$ measured at each site with that calculated by the WRF model. For Garraf and Monegros, the measurements were made above the low shrub vegetation; for Prades and Montseny, the flux was measured in a clearing below the canopy within a forest landscape. Agreement was very good where the measurement fetch was similar to the surrounding landscape (Garraf and Monegros).

$(m / z 45)$, acetone $(m / z 59)$, acetic acid $(m / z 61)$, isoprene $(m / z 69)$, and monoterpenes $(m / z 81,137)$; each of these VOCs have biogenic emission sources).

A logarithmic curve was fitted to the gradient measurements. Where the curve fit was judged in good agreement with the logarithmic fit (on the basis of a subjectively imposed Pearson's correlation coefficient of $r^{2}>0.5$ ), the profile was used in a subsequent gradient-flux calculation.

Edwards et al. (2005) present an expression to calculated gradient fluxes for non-neutral atmospheric stability condition (most commonly experienced in this study):

Flux $=u^{*} \cdot k \cdot\left(C_{2}-C_{1}\right) /\left(\ln \left(\left(z_{2}-d\right) /\left(z_{1}-d\right)-\Psi_{2}+\Psi_{1}\right)\right.$,

where $u^{*}$ is the friction velocity, $k$ is the von Karman constant (0.4), $C_{1}$ and $C_{2}$ are the scalar concentrations at heights $z_{1}$ and $z_{2}, d$ is the displacement height, and $\Psi_{1}$ and $\Psi_{2}$ are defined for the stability conditions as

$\Psi=-4.7 \cdot(z-d) / L$ for stable conditions,

$\Psi=0$ for neutral conditions, and

$\Psi=2 \cdot \ln \left(\left(1+x^{2}\right) / 2\right)$,

with $x=(1-15 \cdot(z-d) / L)^{0.25}$

for unstable conditions and

$$
\begin{gathered}
L(\text { the Monin-Obukhov length })= \\
-\left(u^{*} 3 \cdot T \cdot \rho \cdot C_{p}\right) /(k \cdot g \cdot H) .
\end{gathered}
$$

In Eq. (6), $T$ is atmospheric temperature, $\rho$ is the air density, $C_{p}$ is the specific heat of air, $g$ is the acceleration due to 
gravity $\left(9.8 \mathrm{~m} \mathrm{~s}^{-2}\right), k$ is the von Karman constant, and $H$ is the sensible heat flux. Fortunately, $L$ is an output of the WRF model calculation and its sign $(+$ or -$)$ indicates stable and unstable stability conditions, respectively. Also, $d \ll z$ for the balloon profiles.

Not all profiles produced an acceptable logarithmic fit. This was likely a consequence of the complexity of the terrain, the non-uniform distribution of vegetation and the short sampling time. Calculations showed that for most profiles, the $100 \mathrm{~m}$ sample was collected within the surface, constantflux layer.

\subsubsection{MEGAN biogenic emission model with site-specific emission-capacity observations}

An estimate of landscape emissions was also produced using in an inventory approach. The canopy-scale MEGAN emission factors used for this approach were based on leaf and branch-scale emission measurements (Llusia et al., 2013) that were extrapolated to the canopy-scale using site-specific land cover data and the MEGAN canopy environment model. MEGAN includes light, temperature, leaf age, and leaf area index controls over the emissions of isoprene and other biogenic emissions. The details of the estimation with MEGAN were described in Peñuelas et al. (2013).

\section{Results and discussion}

Figure $3 \mathrm{a}$ and $\mathrm{b}$ presents the flux estimate comparison of the three techniques for the four sites visited in July 2010. Displayed are estimates made for isoprene and the total of monoterpenes. Only isoprene, monoterpenes, and methanol were measured by the mixed layer variance technique and, therefore, allow the direct comparison with the gradient technique; the inventory technique did not consider methanol emissions.

Fluxes were also computed from the gradients of several oxygenated VOCs. In the case of methanol, estimates of emissions were calculated from both the gradient and variance techniques and are shown in Fig. 4. Acetaldehyde, acetone, and acetic acid were not measured during the $30 \mathrm{~min}$ MLV experiments. Their fluxes were computed only by the gradient techniques and are shown in Table 1 along with the fluxes of other VOCs from the SLG technique. Fluxes of methanol, acetic acid, isoprene, and terpenes were typically upward from the surface.

Uncertainties in the fluxes were estimated for each technique. For the MEGAN inventory technique, only the major species were included in the flux estimation; these comprised more than $75 \%$ of the leaf biomass of the area surveyed in Montseny and Prades, but less than $25 \%$ in Garraf and Monegros, where vegetation is not characterized by one or a few dominant species. For Garraf and Monegros, it was assumed
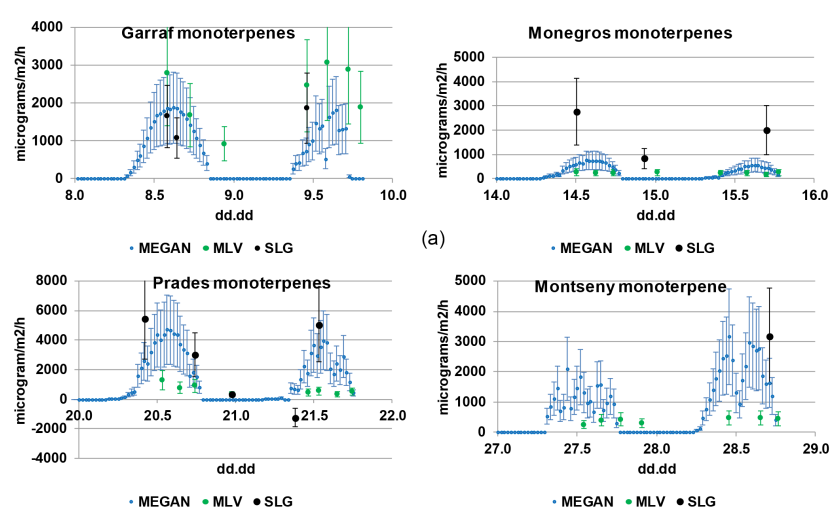

(a) -MEGAN $\cdot$ MLV • SLG
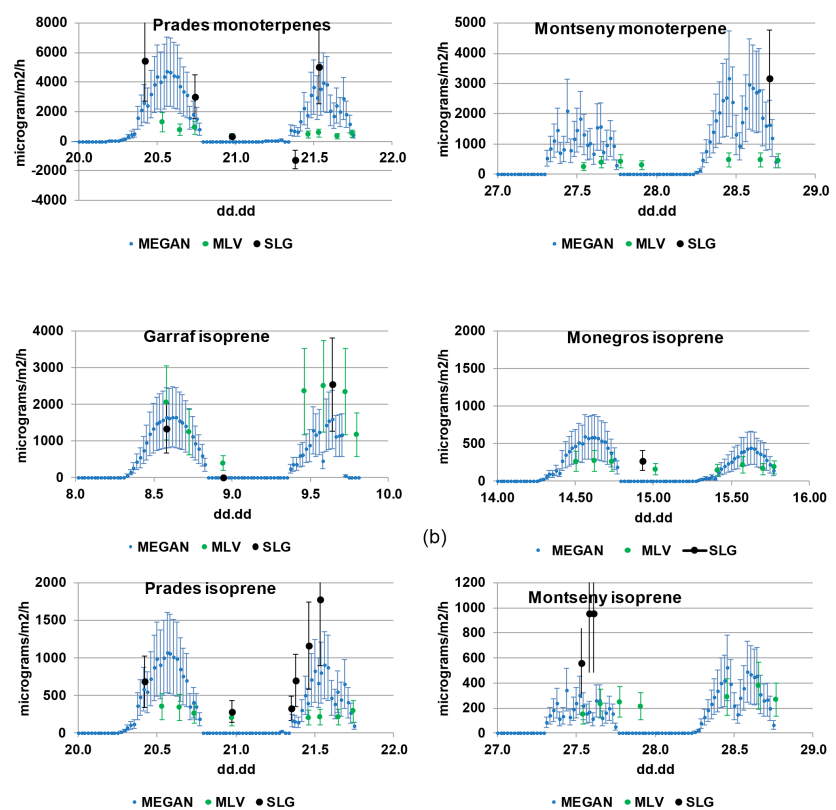

(b) MEGAN MLV $\rightarrow$ SLG

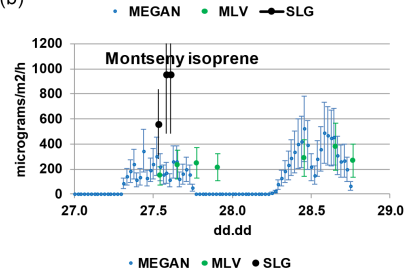

Figure 3. Comparison of the estimates of the MEGAN model with the surface layer gradient and the mixed layer variance techniques for the fluxes of (a) monoterpenes and (b) isoprene.

that the remaining species emitted, on average, at rates similar to the species studied.

Emission estimates were based on the emission capacity of a few individual leaves of major species. Significant variability of the emission capacity among leaves and individuals of a species has been recognized. In the case of isoprene-emitting oaks, the standard deviation of emission capacities was typically around $30 \%$ of the mean value measured (Geron et al., 2001). Isoprene, however, is not stored in the leaves, but is emitted soon after it is produced. For monoterpene-emitting species, where the terpenes may be stored in the leaves or needles, uncertainties are often much higher due to disturbance of the storage structures during the measurement (Niinemets et al., 2011).

The extrapolation of the emissions from the leaf-level to landscape-level emissions includes other uncertainties. The major environmental variables of light and temperature are included in the extrapolation; the dependence of the emissions on these variables was observed only for the major species identified in the study areas (Llusia et al., 2013). Other important variables, such as insect or wind disturbance, water stress, etc., were not noted, but could have significant influence on emissions. Guenther (2013) assessed the uncertainties associated with biogenic VOC emission 
Table 1. Daytime (09:00-17:00 LT) fluxes of several VOCs estimated from the gradient technique $\left(\mu \mathrm{g} \mathrm{m}^{-2} \mathrm{~h}^{-1}\right)$. Negative values indicate deposition to the surface; positive values indicate emission from the surface. Quarters Q1 and Q3 are the limits of interquartile ranges of the estimates from the gradients (Q2 is the median value). The fraction of the measured profiles that provided an acceptable logarithmic curve fit $\left(r^{2}>0.5\right)$ and were subsequently used in the gradient flux calculation is shown (Q2 is the median value, bold).

\begin{tabular}{|c|c|c|c|c|c|c|c|}
\hline & & methanol & acetaldehyde & acetone & $\begin{array}{r}\text { acetic } \\
\text { acid }\end{array}$ & isoprene & terpene \\
\hline \multirow[t]{4}{*}{ Garaff } & Q1 & 500 & -2400 & 500 & 1300 & -2000 & 400 \\
\hline & Q2 & 1050 & -1800 & 650 & 1750 & 1350 & 1350 \\
\hline & Q3 & 1400 & -1550 & 3650 & 2950 & 1950 & 1700 \\
\hline & $\mathrm{f}$ & $4 / 8$ & $3 / 8$ & $6 / 8$ & $5 / 8$ & $4 / 8$ & $3 / 8$ \\
\hline \multirow[t]{4}{*}{ Monegros } & Q1 & 2100 & $\mathrm{a}$ & 350 & -1000 & $\mathrm{~b}$ & $\mathrm{~b}$ \\
\hline & Q2 & 2250 & 384 & 450 & 100 & b & b \\
\hline & Q3 & 2500 & $\mathrm{a}$ & 500 & 1750 & $\mathrm{~b}$ & $\mathrm{~b}$ \\
\hline & $\mathrm{f}$ & $3 / 11$ & $1 / 11$ & $5 / 11$ & $6 / 11$ & $0 / 6$ & $0 / 6$ \\
\hline \multirow[t]{4}{*}{ Prades } & Q1 & 250 & 600 & 400 & 1100 & 1950 & 400 \\
\hline & Q2 & 2050 & 1100 & 1100 & 2100 & 4050 & 700 \\
\hline & Q3 & 2250 & 1250 & 2400 & 4900 & 5150 & 1050 \\
\hline & $\mathrm{f}$ & $3 / 8$ & $4 / 8$ & $6 / 8$ & $6 / 8$ & $4 / 8$ & $6 / 8$ \\
\hline \multirow[t]{4}{*}{ Montseny } & Q1 & -600 & -1000 & 2050 & 2950 & -1450 & -500 \\
\hline & Q2 & 250 & -800 & 2600 & 5600 & 1050 & $\mathbf{5 5 0}$ \\
\hline & Q3 & 2050 & 1800 & 6200 & 6600 & 5600 & 950 \\
\hline & $\mathrm{f}$ & $4 / 8$ & $3 / 8$ & $6 / 8$ & $4 / 8$ & $4 / 8$ & $4 / 8$ \\
\hline
\end{tabular}

a one value; ${ }^{b}$ no determination; f: profiles used in calculation/total profiles.
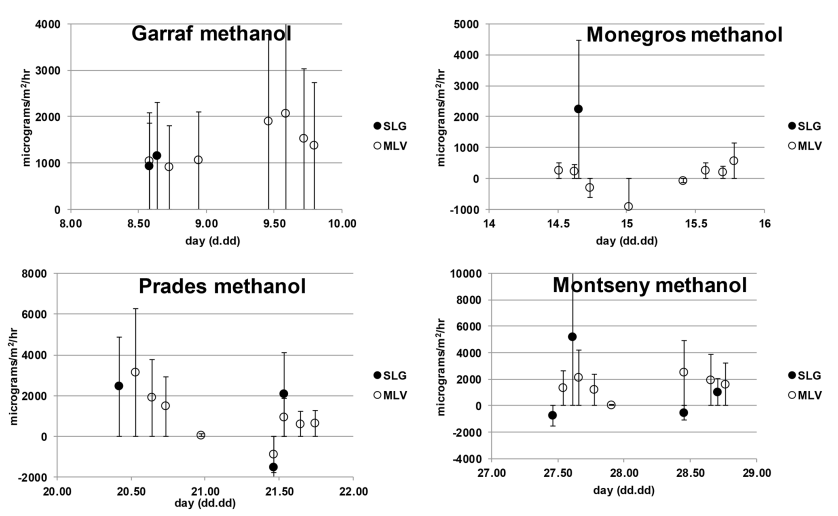

Figure 4. Comparison of the fluxes of methanol estimated by the surface layer gradient and the mixed layer variance techniques.

estimates and noted that it is difficult to quantify the uncertainty of the inventory estimate. Previous studies that assign uncertainties of a factor of 2 or more (Lamb et al., 1987) and comparisons with above-canopy flux measurements and inverse modeling using satellite observations indicate that isoprene fluxes tend to be within about $50 \%$, although there are exceptions (Guenther, 2013). While considerable uncertainties are associated with driving variables (e.g., weather conditions and vegetation type and cover fraction) and emission response to these variables, the largest uncertainty is associated with the emission rate associated with different vegetation types. While there are some general patterns that have been observed, such as shrublands having higher monoterpene emissions than grasslands and broadleaf trees having higher isoprene emissions than needle-leaf trees, there are also many important exceptions, and measurements are required to quantify landscape average emission factors that are representative of major vegetation types within a modeling domain. There are few observations of landscapescale emission factors due to the considerable expense and effort associated with the measurement approaches that have previously been applied.

The MLV method had some significant errors. The height of the balloon during the standard deviation measurements varied as much as $20 \%$ below the maximum (usually $100 \mathrm{~m}$ ) as a result of strong, occasional downward eddies. Also, flow through the balloon sampling tube to the mass spectrometer was not completely turbulent (Reynolds number $\sim 1600$ vs. $>2500$ for turbulent flow). Consequently, the standard deviation contribution from the smallest eddies was probably excluded; this may result in a small underestimation of the flux (Lenschow and Raupach, 1991; Massman, 1991). The launch site for the balloon profiles was necessarily located in a clearing in the landscapes; the clearing may have represented a significant fraction of the footprint of the measurements; this suggests that the resulting fluxes may be underestimated. Uncertainties associated with 
non-uniform species distribution and complex terrain were not determined. Although VOC emissions advected from different wind sectors may have been significantly different, the emission estimates, on average, were assumed to be representative of the extended landscape.

Calibrations of the PTRMS were performed several times each day and were estimated to be on the order of $10 \%$. The uncertainty of the MLV estimates was also set at a factor of 2 to compare with the MEGAN estimate uncertainty.

The surface layer gradient technique requires an estimation of eddy transport from an expression derived for a flat, uniform surface, which was not the case here. However, for those profiles where a logarithmic fit of the data for each VOC gave a correlation coefficient $\left(r^{2}\right)$ greater than $50 \%$, fluxes were computed according to the SLG expressions (Eqs. 2-6). The sampling time at each level (10 min) was considerably less than the scale of the largest eddies in the boundary layer $(\sim 30 \mathrm{~min})$, which may be partially responsible for curve fits of lower quality. Again, uncertainties associated with vegetation distribution and topography were not estimated. The uncertainty of the surface layer gradient flux estimate was also set at a factor of 2 to compare with the MLV and MEGAN approaches.

Comparison of the results of the SLG, MLV, and inventory techniques are shown in Figs. 3a, b, and 4. Although the inventory results (MEGAN) are calculated over the $24 \mathrm{~h}$ period, the results are biased by the incomplete determination of species distribution and, consequently, may not accurately represent landscape-level emissions. There does not seem to be a bias, high or low, between the MLV and the SLG techniques. There were more determinations for the MLV technique, where results were estimated for most $1 / 2 \mathrm{~h}$ periods. A significant percentage of SLG profiles were not used to calculate fluxes since the curve fit for individual profiles showed a poor correlation with the data. The estimated uncertainties of each of the techniques that are compared in the figures are on the order of a factor of 2 . This is, however, similar to or smaller than uncertainties of emission capacities for individual species and landscapes often cited in the literature. There was agreement among the methods, within the uncertainties estimated, in many comparisons. It is assumed that a comparison of the techniques in a landscape with a horizontally homogeneous distribution of vegetation would produce better agreement.

The SLG technique allowed the estimation of the fluxes of additional VOCs. The MLV technique requires a high frequency measurement of individual ions, which restricted the number of VOCs that could be included. Table 1 shows the median, as well as the limits, of the central $50 \%$ of daytime (09:00 to 17:00 LT) fluxes computed for several VOCs. Isoprene and monoterpenes, as well as acetic acid, were always emitted from the landscapes of all sites during the daytime. However, there several occasions when deposition of isoprene and monoterpenes occurred; during those periods both isoprene and terpenes simultaneously were deposited.
However, the conditions influencing the deposition were not observed. Emission or deposition of other BVOCs varied among the sites.

\section{Conclusions}

Tethered-balloon PTRMS sampling techniques (mixed layer variance, and surface layer gradient) provided characterization of landscape-scale estimates of isoprene, monoterpene, and several other BVOC emissions that were within a factor of two, at the four sites studied, for the two independent techniques. This was within the uncertainty of the measurements and indicates reasonable agreement between the two techniques.

Comparison with the inventory technique, which employed site-specific leaf and branch enclosure measurements and biomass data and the MEGAN model to adjust for environmental influences, often differed by as much as a factor of 2 in comparison with the balloon-PTRMS technique estimates. Using these observations to constrain BVOC emission factors would result in significant changes in model emissions, suggesting lower isoprene and higher monoterpenes from the Garraf shrubland, lower isoprene and monoterpenes from the Prades oak forest, and lower monoterpenes from the Monegros shrubland and Montseny beech forest.

Although the theory for the mixed layer variance and surface layer gradient flux formulations assumes a homogeneous species distribution within a horizontal landscape, which was not the case at these sites, these results suggest that this approach can provide a reasonable estimate of landscape-scale emissions that is useful for parameterizing emission models. For example, this approach was used for this study to characterize four different landscapes within a 3-week period. The tethered-balloon PTRMS sampling approach eliminates the need to erect and instrument towers and is readily portable. It is also considerably less laborious than the inventory technique, which requires identification and quantification of emitting species and the determination of the environmental dependence of the independent variables that affect emissions. This is especially true in a biologically diverse landscape. In addition, the fluxes of several oxygenated VOCs, difficult to measure using stored samples and chromatographic techniques, can be more easily quantified. Consequently, we conclude that a tethered-balloon PTRMS sampling approach using the mixed layer variance and the surface layer gradient techniques may be suitable for surveying over a relatively short time period in most locations and could increase the availability of observed landscape-scale emission factors for parameterizing biogenic emission models for the many landscapes where few or no emission measurements have been made.

Acknowledgements. This research was supported by the Spanish Government grants CGL2010-17172/BOS and Consolider-Ingenio Montes CSD2008-00040, and by the Catalan Government project 
SGR 2009-458. The National Center for Atmospheric Research is sponsored by the National Science Foundation.

Edited by: M. Sipilä

\section{References}

Chen, F., Janjic, Z., and Mitchell, K.: Impact of atmospheric surface-layer parameterizations in the new land-surface scheme of the NCEP mesoscale Eta model, Bound.-Lay. Meteorol., 85, 391-421, 1997.

Chou, M. D., Suarez, M. J., Ho, C. H., Yan, M. M. H., and Lee, K. T.: Parameterizations for cloud overlapping and shortwave single-scattering properties for use in general circulation and cloud ensemble models, J. Climate, 11, 202-214, 1998.

Edwards, G. C., Rasmussen, P. E., Schroeder, W. H., Wallace, D. M., Halfpenny-Mitchell, L., Dias, G. M., Kemp, R. J., and Ausma, S.: Development and evaluation of a sampling system to determine gaseous Mercury fluxes using an aerodynamic micrometeorological gradient method, J. Geophys. Res., 110, D10306, doi:10.1029/2004JD005187, 2005.

Geron, C., Harley, P. H., and Guenther, A. B.: Isoprene emission capacity of US tree species, Atmos. Environ, 35, 334-3352, 2001.

Greenberg, J. P., Guenther, A., Zimmerman, P., Baugh, W., Geron, C., Davis, K., Helmig, D., and Klinger, L. F.: Tethered balloon measurements of biogenic VOCs in the atmospheric boundary layer, Atmos. Environ., 33, 855-867, 1999.

Grell, G. A. and Devenyi, D.: A generalized approach to parameterizing convection combining ensemble and data assimilation techniques, Geophys. Res. Lett., 29, 38.1-38.4, doi:10.1029/2002GL015311, 2002.

Grell, G. A., Peckham, S. E., Schmitz, R., McKeen, S. A., Frost, G., Skamarock, W. C., and Eder, B.: Fully coupled "online" chemistry within the WRF model, Atmos. Environ., 39, 6957-6975, 2005.

Guenther, A.: Upscaling Biogenic Volatile Compound Emissions from Leaves to Landscapes, in: Biology, controls and models of tree volatile organic compound emissions $(V-X)$, Niinemets, Ülo; Monson, edited by: Russell, K., Berlin: Springer-Verlag, 2013.

Guenther, A., Greenberg, J., Harley, P., Helmig, D., Klinger, L., Vierling, L., Zimmerman, P., and Geron, C.: Leaf, branch, stand and landscape scale measurements of volatile organic compound fluxes from US woodlands, Tree Physiol., 16, 17-24 1996a.

Guenther, A., Baugh, W., Davis, K., Hampton, G., Harley, P., Klinger, L., Vierling, L., Zimmerman, P., Allwine, E., Dilts, S., Lamb, B., Westberg, H., Baldocchi, D., Geron, C., and Pierce, T.: Isoprene fluxes measured by enclosure, relaxed eddy accumulation, surface layer gradient, mixed layer gradient, and mixed layer mass balance techniques, J. Geophys. Res.-Atmos., 101, 18555-18567, 1996b.

Guenther, A., Karl, T., Harley, P., Wiedinmyer, C., Palmer, P. I., and Geron, C.: Estimates of global terrestrial isoprene emissions using MEGAN (Model of Emissions of Gases and Aerosols from Nature), Atmos. Chem. Phys., 6, 3181-3210, doi:10.5194/acp-63181-2006, 2006.

Guenther, A. B., Jiang, X., Heald, C. L., Sakulyanontvittaya, T., Duhl, T., Emmons, L. K., and Wang, X.: The Model of Emissions of Gases and Aerosols from Nature version 2.1 (MEGAN2.1): an extended and updated framework for modeling biogenic emissions, Geosci. Model Dev., 5, 1471-1492, doi:10.5194/gmd-51471-2012, 2012.

Hong, S.-Y. and Pan, H.-L.: The WRF single-moment 6-class microphysical scheme (WSM6), J. Korean Meteor. Soc., 42, 129151, 2006.

Jiang, X., Wiedinmyer, C., Chen, F., Yang, Z.-L., and Chun-Fung Lo, J.: Predicted impacts of climate and land use change on surface ozone in the Houston, Texas area, J. Geophys. Res., 113, D20313, doi:10.1029/2008JD009940, 2008.

Kaimal, J. C. and Finnigan, J. J.: Atmospheric Boundary Layer Flows: Their Structure and Measurement, Oxford University Press, Oxford, 1994.

Karl, T., Guenther, A., Yokelson, R. J., Greenberg, J., Potosnak, M., Blake, D. R., and Artaxio, P.: The tropical forest and fire emissions experiment: Emission, chemistry, and transport of biogenic volatile organic compounds in the lower atmosphere over Amazonia, J. Geophys. Res.-Atmos., 112, D18302, doi:10.1029/2007jd008539, 2007.

Lamb, B., Guenther, A., Gay, D., and Westberg, H.: A National Inventory of Biogenic Hydrocarbon Emissions, Atmos. Environ., 21, 1695-1705, 1987.

Lenschow, D. H.: Micrometeorological techniques for measuring biosphere-atmosphere trace gas exchange, in Biogenic Trace gases: measuring emissions from soil and water, Matson, P. A. and Harriss, R. C., Blackwell Science, Ltd., Oxford, UK, chapter 5, 126-163, 1995.

Lenschow, D. H. and Raupach, M. R.: The attenuation of fluctuations in scalar concentrations through sampling tubes, J. Geophys. Res., 96, 15259-15268, 1991.

Lin, Y. L., Farley, R. D., and Orville, H. D.: Bulk parameterization of the snow field in a cloud model, J. Clim. Appl. Meteorol., 22, 1065-1092, 1983.

Lindinger, W., Hansel, A., and Jordan, A.: On-line monitoring of volatile organic compounds at ppt levels by means of protontransfer-reaction mass spectrometry (PTR-MS) medical applications, food control and environmental research, Int. J. Mass Spec. Ion Proc., 173, 191-241, 1998.

Llusia, J., Peñuelas, J., Guenther, A., and Rapparini, F.: Seasonal variations in terpene emission factors of dominant species in four ecosystems in NE Spain, Atmos. Environ., 70, 149-158, 2013.

Massman, W. J.: The attenuation of concentration fluctuations in turbulent flow through a tube, J. Geophys. Res., 96, 1526915273, 1991.

Mlawer, E. J., Taubman, S. J., Brown, P. D., Iacono, M. J., and Clough, A. A.: Radiative transfer for inhomogeneous atmosphere: RRTM, a validated correlated-k model for the longwave, J. Geophys. Res., 102, 16663-16682, 1997.

Niinemets, Ü., Kuhn, U., Harley, P. C., Staudt, M., Arneth, A., Cescatti, A., Ciccioli, P., Copolovici, L., Geron, C., Guenther, A., Kesselmeier, J., Lerdau, M. T., Monson, R. K., and Peñuelas, J.: Estimations of isoprenoid emission capacity from enclosure studies: measurements, data processing, quality and standardized measurement protocols, Biogeosciences, 8, 2209-2246, doi:10.5194/bg-8-2209-2011, 2011.

Peñuelas, J., Guenther, A., Rapparini, F., Llusia, J., Filella, I., Seco, R., Estiarte, M., Mejia-Chang, M., Ogaya, R., Ibañez, J., Sardans, J., Castaño, L. M., Turnipseed, A., Duhl, T., Harley, P., Vila, J., Estavillo, J. M., Menéndez, S., Facini, O., Baraldi, R., Geron, 
C., Mak, J., Patton, E. G., Jiang, X., and Greenberg, J.: Intensive measurements of gas, water, and energy exchange between vegetation and troposphere during the MONTES campaign in a vegetation gradient from short semi-desertic shrublands to tall wet temperate forests in the NW Mediterranean Basin, Atmos. Environ., 75, 348-364, 2013.

Skamarock, C. W., Klemp, J. B., Dudhia, J., Gill, D. O., Barker, D. M., Wang, W., and Powers, J. G.: A description of the Advanced Research WRF version 2, NCAR Technical Note, NCAR/TN468+STR, June 2005.

Stockwell, W. R., Middleton, P., Chang, J. S., and Tang, X.: The second generation regional Acid Deposition Model chemical mechanism for regional air quality modeling, J. Geophys. Res., 95, 16343-16367, 1990
Webb, E. K., Pearman, G. I., and Leuning, R.: Correction of flux measurements for density effects due to heat and water vapour transfer, Q. J. Roy. Meteorol. Soc., 106, 85-100, 1980.

Wesley, M. L.: Parameterization of surface resistance to gaseous dry deposition in regional numerical models, Atmos. Environ., 23, 1293-1304, 1989.

Zhang, Q., Streets, D. G., Carmichael, G. R., He, K. B., Huo, H., Kannari, A., Klimont, Z., Park, I. S., Reddy, S., Fu, J. S., Chen, D., Duan, L., Lei, Y., Wang, L. T., and Yao, Z. L.: Asian emissions in 2006 for the NASA INTEX-B mission, Atmos. Chem. Phys., 9, 5131-5153, doi:10.5194/acp-9-5131-2009, 2009.

Zhao, J. and Zhang, R. Y.: Proton transfer reaction rate constants between hydronium ion $\left(\mathrm{H}_{3} \mathrm{O}^{+}\right)$and volatile organic compounds, Atmos. Environ., 38, 2177-2185, 2004. 